REVIEW

\title{
Early referral recommendations for ankylosing spondylitis (including pre-radiographic and radiographic forms) in primary care \\ J Sieper, M Rudwaleit
}

Ann Rheum Dis 2005;64:659-663. doi: 10.1136/ard.2004.028753

An earlier diagnosis of ankylosing spondylitis (AS) is required because there is still a 5-7 year delay between first symptoms and diagnosis, and new effective treatments are available for active disease. Primary care physicians need easy to apply parameters to help them identify patients with suspected AS for onward referral. The best measures found were inflammatory back pain and HLAB27 positivity.

See end of article for authors' affiliations

Correspondence to: Medical Department I Rheumatology, Charitè, University Medicine Berlin, Germany, Hindenburgdamm 30, 12200 Berlin, Germany; joachim.sieper@charite.de

Accepted 27 October 2004 Published Online First 4 November 2004
A mong the inflammatory rheumatic diseases the longest delay between the onset of symptoms and making the diagnosis is currently found for ankylosing spondylitis (AS): in several studies from different countries a mean duration of about 7 years has been reported. ${ }^{12}$ The mean age of onset of symptoms is in the mid-20s, thus at the normally most productive time of life. If undiagnosed and untreated, or not treated effectively enough, continuous pain, stiffness, and fatigue are the consequences. Furthermore, a potentially progressive loss of spinal mobility and function, together with the acute symptoms, cause a reduction in the quality of life and an increase in direct and indirect medical costs. Because the prevalence, including the early forms of the disease, has been estimated to be between 0.2 and $1 \%,^{3-5}$ late diagnosis and inadequate treatment have also potentially socioeconomic consequences.

\section{TREATMENT OPTIONS FOR AS}

Until recently, the treatment options for AS were limited. Regular physiotherapy and treatment with non-steroidal anti-inflammatory drugs (NSAIDs) were the only available symptomatic treatments. Other treatment options, such as disease modifying antirheumatic drugs or steroids, which are quite effective in other chronic inflammatory diseases such as rheumatoid arthritis, have no effect or only a very limited effect. ${ }^{67}$ Thus, although an early and correct diagnosis was wanted to avoid unnecessary diagnostic and therapeutic procedures (such as disc surgery) this did not seem to be so urgent for many doctors and patients because of the lack of therapeutic choices.

This has changed now: NSAIDs should probably be taken more regularly once a diagnosis has been made, and tumour necrosis factor blockers offer an exciting new possibility for effective treatment and, hopefully, may also have the potential to stop progression. Until now it was not clear whether NSAID treatment has an effect on the long term outcome. A most recent study showed that patients with AS treated continuously over 2 years with a daily dose of NSAIDs had less radiological progression than those patients who took NSAIDs only irregularly on demand. ${ }^{8}$ Furthermore, as has been pointed out first by Bernard Amor from France, about $75 \%$ of patients with AS show a good or very good response to a full dose of NSAIDs within 48 hours, in contrast with only $15 \%$ of patients with mechanical back pain. ${ }^{9}$ This clear difference in the response rate between patients with AS and patients with chronic mechanical back pain was recently confirmed by us (Rudwaleit et al, unpublished). Thus, because of the good efficacy in the treatment of acute symptoms and because of the potential to retard long term damage, patients with active AS with inflammatory back pain, in contrast with patients with mechanical low back pain, should probably be treated long term with NSAIDs, once the diagnosis is made. A cox-II selective NSAID may be the preferred choice for long term treatment because gastric side effects are less common than in patients treated with non-selective NSAIDs. ${ }^{10}$

\section{"NSAIDs taken regularly may slow radio- graphic progression in $\mathrm{AS}^{\prime \prime}$}

However, most importantly in the context of this discussion, it was recently shown that the tumour necrosis factor $\alpha$ blocking agents infliximab $^{1112}$ and etanercept ${ }^{1314}$ have a surprisingly strong and fast effect on almost all aspects of active disease, including acute phase reactants, function, spinal mobility, peripheral arthritis, enthesitis, acute inflammation as detected by magnetic resonance imaging (MRI), ${ }^{15}$ and bone density. ${ }^{16}$ In the various studies using these two compounds a $50 \%$ improvement of the disease activity could be demonstrated in about half of the treated patients who were refractory to NSAIDs and physiotherapy. It is also important to note that $72 \%$ patients with a disease duration of $<10$ years showed at least $50 \%$ improvement

Abbreviations: AS, ankylosing spondylitis; CRP, C reactive protein; ESR, erythrocyte sedimentation rate; IBP, inflammatory back pain; LR, likelihood ratio; MRI, magnetic resonance imaging; NSAIDs, non-steroidal antiinflammatory drugs 
of the Bath AS Disease Activity Index (BASDAI), clearly higher than for patients with a longer disease duration. ${ }^{17}$ This finding makes an early diagnosis even more essential.

\section{DELAY IN DIAGNOSIS OF AS}

For the long delay in the diagnosis of AS there are two major reasons: $(a)$ because there is no unique clinical symptom or laboratory test to make the diagnosis it is a real challenge to identify the $5 \%$ of patients ${ }^{18}$ with an axial spondyloarthritis (SpA) (including AS) among the great numbers of patients with chronic low back pain, most of them with functional back pain, ${ }^{19}$ seen by the primary care physician; (ii) until now the presence of radiological sacroiliitis was essential for the diagnosis of AS, according to the modified New York criteria. ${ }^{20}$ However, it may take several years of inflammation of the sacroiliac joint before radiological damage can be demonstrated. ${ }^{21}$ The presence of inflammation in early disease could indeed be nicely proved in recent years by MRI. $^{22}$

\section{"Tests to diagnose AS early before radiographic changes occur are needed"}

We have recently suggested an approach for making a diagnosis early and reliably by combining several clinical, laboratory, and imaging parameters before radiologically visible changes occur. ${ }^{23}$ Thus, the considerations presented below should be of relevance both for patients with established AS (according to the modified New York criteria $^{20}$ ) and for patients with "pre-radiographic early $\mathrm{AS}^{\prime}$. We have proposed the term "axial SpA" for these two groups, ${ }^{23}$ similar to the inflammatory back pain (IBP) group which are included in the patients with spondyloarthropathy described previously by the European Spondylarthropathy Study Group $\left(\mathrm{ESSG}^{24}\right)$. No recommendations for referral strategies to identify these patients early by primary care physicians have been developed so far, certainly also one of the reasons for the delay in diagnosis.

\section{HOW CAN SUCH SCREENING BE PERFORMED BY PRIMARY CARE PHYSICIANS?}

Any approach suggested to identify patients with axial SpA in primary care has to be feasible if it is meant to be applied in a busy daily practice. Measures which can be used for early referral should be developed along the following lines: (a) they should be easy to use. Thus, one single parameter is preferable to several parameters or a combination of parameters; $(b)$ it should be relatively easy to decide on whether this parameter is positive or negative, also by a primary care physician who does not have a lot of experience with this disease; (c) because it is used for screening the parameter/test should not be expensive; $(d)$ a parameter used for screening should be highly sensitive, thus, only a small percentage of patients should be missed if the parameter is negative. Thus, if a parameter has a sensitivity of $75 \%$ for a certain diagnosis, $25 \%$ of patients will be missed if negative, if the sensitivity is $60 \%$, already $40 \%$ of patients will be missed, independently of whether this parameter has a high specificity. Therefore, parameters with a low sensitivity cannot be used for this purpose; (e) because patients with a positive screening test have to be referred to a specialist (normally a rheumatologist) the number of patients to be seen by the rheumatologist to make the diagnosis in one patient should not be too large. This number is determined by the post-test probability of having the disease when the test parameter is positive, which depends on the pretest probability of the disease in a given population and the sensitivity and specificity of the test parameter. This methodological approach has been discussed in more detail recently. ${ }^{23}$

The sensitivity and specificity can be combined in the likelihood ratio (LR), which has the advantage of combining both figures in one value and is defined as follows:

Likelihood ratio $(\mathrm{LR})=($ sensitivity $) / 1-($ specificity $)$

if the parameter is present. Thus, the test parameter with the highest LR will result in the highest post-test probability if positive and in the lowest number of patients to be seen by a rheumatologist to make the diagnosis in one patient. For example, if the post-test probability is $20 \%$ for a given parameter the number of patients seen to make a diagnosis in one will be five, if this is $50 \%$ the diagnosis will be made in one out of two patients. Thus, an ideal screening parameter (test) should have a good sensitivity, but also a good LR.

\section{SELECTION OF PARAMETERS FOR SCREENING}

To apply sensitivity and specificity for calculation of the posttest probability, knowledge of the pretest probability (prevalence of the disease) in a given population is necessary. In our calculations we assume a pretest probability of $5 \%$ for a patient with chronic back pain with axial SpA when seen by a primary care physician. ${ }^{18}$ Importantly, we suggest that the screening procedure proposed here should be used only in patients with chronic back pain of $>3$ months' duration and only in patients in whom the first symptoms of back pain started before the age of 45 . Because AS starts rarely (in $<4 \%$ ) in patients older than $40^{1}$ we do not lose a great deal of sensitivity but may increase the proportion of patients with axial SpA. Table 1 shows the clinical, laboratory, and imaging parameters which are normally used to make a diagnosis of axial SpA.

The figures for sensitivity and specificity are derived from published studies, and were presented in more detail previously. ${ }^{23}$

\section{CLINICAL PARAMETERS \\ Inflammatory back pain}

Choosing clinical parameters for screening is attractive because their determination is not expensive. The clinical symptom of IBP has been suggested as a leading clinical symptom for AS. ${ }^{23-25}$ There are no costs for the assessment of this measure and with a sensitivity of $75 \%{ }^{23}$ only about $25 \%$ of patients with axial SpA who do not have this symptom will be missed. When clinical symptoms of IBP are present in a patient with chronic low back pain the post-test probability for this patient of having the diagnosis of axial SpA is $14 \%{ }^{23}$ Thus, using IBP as referral parameter a diagnosis of AS can be made in about $1 / 7$ patients seen by the rheumatologist (table 1). One drawback of using this parameter for referral is that in up to about one third of patients (according to our experience) it cannot clearly be decided whether the back pain is inflammatory or not. Furthermore, assessment of IBP by the physician needs some clinical experience, which cannot always be expected to be present among primary care physicians.

\section{Response to treatment with NSAIDs}

Similarly, a good or very good response to treatment with a full dose of NSAIDs in 48 hours can be used as a referral parameter. With an assumed similar sensitivity of $75 \%{ }^{823}$ again only about $25 \%$ of patients would be missed and in $1 / 5$ patients the diagnosis of axial SpA can be made by the rheumatologist if we assume an LR of 5, with a resulting post-test probability of $21 \%$ (table 1 ). If the cost of the prescription for an NSAID is not included there are also no costs for this screening test. Because the patient judges how effective the NSAID treatment is, this measure might be 
Table 1 Clinical, laboratory, and imaging parameters which should be considered for screening of patients with chronic low back pain * for axial SpA by primary care physicians. For more details see text.

\begin{tabular}{|c|c|c|c|c|c|c|c|c|}
\hline Parameters & $\begin{array}{l}\text { Sensitivity } \\
\text { (\%) }\end{array}$ & $\begin{array}{l}\text { Specificity } \\
(\%)\end{array}$ & $\begin{array}{l}\text { Likelihood } \\
\text { ratio }\end{array}$ & $\begin{array}{l}\text { Post-test } \\
\text { probability } \\
\text { of having } \\
\text { the disease } \\
(\%)\end{array}$ & $\begin{array}{l}\text { Number of } \\
\text { patients to be seen } \\
\text { to make a } \\
\text { diagnosis of } \\
\text { axial SpA }\end{array}$ & $\begin{array}{l}\text { Cost for } \\
\text { the test }\end{array}$ & $\begin{array}{l}\text { Ease of inter- } \\
\text { pretation }\end{array}$ & $\begin{array}{l}\text { Overall } \\
\text { rating }\end{array}$ \\
\hline \multicolumn{9}{|l|}{ Clinical parameters } \\
\hline Response to NSAID & 75 & 85 & 5 & 21 & 5 & $\begin{array}{l}\text { Low } \\
\text { Low }\end{array}$ & $\begin{array}{l}\text { Good } \\
\text { Good }\end{array}$ & + \\
\hline Uveitis & 15 & 98 & 7.3 & 28 & 4 to 3 & Low & Good & 0 \\
\hline Family history & 25 & 96 & 6.4 & 25 & 4 & Low & Moderate & 0 \\
\hline Peripheral arthritis & 40 & 90 & 4 & 17 & 4 to 5 & Low & Moderate & 0 \\
\hline \multicolumn{9}{|l|}{ Laboratory parameters } \\
\hline HLA-B27 & 90 & 90 & 9 & 32 & 3 & Moderate & Very good & H+H \\
\hline ESR/CRP & 50 & 80 & 2.5 & 11.6 & 10 & Moderate & Good & 0 \\
\hline \multicolumn{9}{|l|}{ Imaging parameters } \\
\hline MRI (sacroiliitis) & 90 & 90 & 9 & 32 & 3 & High & Moderate & + \\
\hline x Rays (sacroiliitis) & 80 & 80 & 4 & 17.4 & 5 & Moderate & Moderate & + \\
\hline
\end{tabular}

Overall rating whether suitable as a primary simple screening parameter: 0 , not suitable (because of low sensitivity); + , moderate; ++ , good; +++ , very good. ${ }^{*}$ Age of onset of back pain $<45$ years and duration $>3$ months.

ESR, erythrocyte sedimentation rate; CRP, $C$ reactive protein.

easier for the non-specialist to use. To take such a parameter seriously into account as a screening test, the physician has to prescribe a full dose of an NSAID.

None the less, among these two measures we definitely prefer IBP as the screening parameter because it draws the physician's attention to back pain and because patients who show no good response to NSAID but do have axial SpA seem to have a worse prognosis and should thus be preferably referred to the specialist. ${ }^{26}$ None of the other clinical measures listed in table 1 are useful for screening because their sensitivity is too low.

\section{IMAGING PARAMETERS \\ Sacroiliitis}

Sacroiliitis grade 2 bilaterally or grade 3 or higher unilaterally shown by $x$ ray examination is still mandatory to fulfil the currently widely used modified New York criteria for the diagnosis of AS. ${ }^{20}$ However, as was recently shown in a Dutch study, neither the sensitivity nor specificity of radiological sacroiliitis can be regarded as higher than about $80 \%,{ }^{27}$ thus resulting in an LR of 4 and in a post-test probability of no higher than $17 \%$. The radiological exposure has also to be taken into account when considering this parameter for screening a large number of mostly young people.

\section{MRI}

MRI of the sacroiliac joints seems to have a good sensitivity and specificity. ${ }^{22}{ }^{23}$ However, because MRI is very expensive we would currently not recommend this method as a screening test to be applied by the primary care physician. Furthermore, no standardised technique or standardised interpretation of results (positivity/negativity) has been agreed on so far (table 1 ).

None the less, if the primary care physician has evidence of sacroiliitis provided either by $x$ ray examination or MRI investigation in a young patient with chronic low back pain this finding can also be used for referral to the rheumatologist.

\section{LABORATORY PARAMETERS}

Only two laboratory parameters could be taken into account to be used for screening: the acute phase reactants (erythrocyte sedimentation rate (ESR) and/or the $\mathrm{C}$ reactive protein (CRP)) and HLA-B27.

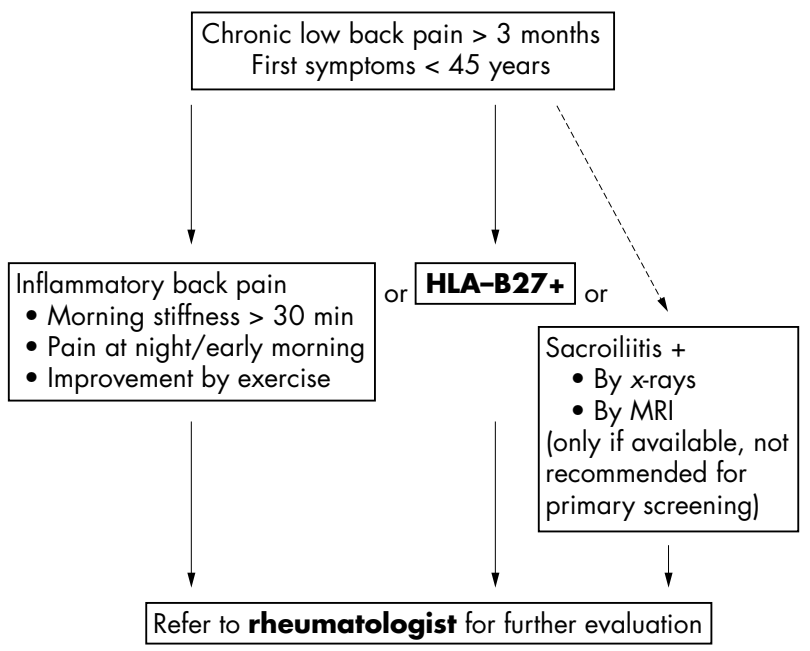

Figure 1 Parameters suitable for screening and early referral of patients with low back pain with axial SpA by primary care physicians to a rheumatologist.

\section{ESR/CRP}

The ESR/CRP are easy to measure but give only a post-test probability of about $12 \%$ if raised (table 1). Of more importance, the sensitivity in patients with AS and early AS is no higher than $50 \%{ }^{23}$ Thus, it is not a suitable parameter for screening.

\section{HLA-B27}

HLA-B27 has a high sensitivity of $90 \%$ (only $10 \%$ of patients are missed), a good LR of 9, and a good post-test probability of $32 \% .{ }^{23}$ Thus, only three patients with chronic low back pain who are HLA-B27 positive have to be seen by the rheumatologist to make the diagnosis in one. The test is easy to handle and to interpret with a clear "positive" or "negative" answer and no variability over time (false negative or positive laboratory testing of HLA-B27 can be assumed to be lower than 5\%). These features make HLA-B27 an ideal test for screening patients with chronic low back pain for axial SpA. HLA-B27 positivity is also one of the factors predicting a bad prognosis, ${ }^{28}$ which makes it more 
important to identify HLA-B27 positivity among patients with axial SpA than HLA-B27 negativity.

The costs obviously are higher than assessing a clinical symptom. HLA-B27 testing costs about $€ 40$ in Germany, which is equivalent to a normal $x$ ray examination of the chest or of the pelvis. In comparison, rheumatoid factor and CRP would be about $€ 15$ each and IgG plus IgM enzyme linked immunosorbent assay (ELISA) test for anti-Borrelia burgdorferi antibodies about $€ 35$. It has also to be taken into account that HLA-B27 testing has to be done only once and that many primary care physicians order it frequently anyway. ${ }^{29}$ In view of this, background HLA-B27 testing of the right patient seems to be cost effective.

Table 1 lists the sensitivities, specificities, LRs, and considerations of feasibility, and costs of each parameter which might be used for screening, together with suggestions on the choice of the best parameter.

\section{DISCUSSION}

In patients with chronic low back pain (duration $>3$ months) with the onset of symptoms at an age $<45$ years two options, based on the data and the considerations presented here, should be proposed to physicians in primary care for screening of patients with axial SpA: $(a)$ the presence of inflammatory back pain or (b) HLA-B27 positivity (fig 1). Screening by HLA-B27 seems to be better than IBP because of higher sensitivity (90\% $v 75 \%$ ), higher specificity (90\% v $75 \%)$, smaller number of patients to be seen to make a diagnosis of axial SpA $(1 / 3 \quad v 1 / 7)$, and the ease of interpretation-that is, whether positive or not. Primary screening by HLA-B27 is only hampered by costs. Thus, if B27 testing is not affordable or available, screening by IBP can be considered as a reasonable alternative.

In the past HLA-B27 was not considered a good measure to use early in a diagnostic approach for patients with axial SpA because, correctly, the majority of patients with low back pain (about two thirds) would not have the diagnosis. ${ }^{30}$ We agree that HLA-B27 should be used in a diagnostic approach only later once the pretest likelihood has been increased to about $30-50 \%$ by the presence of other clinical or imaging parameters. ${ }^{23}{ }^{30}$ However, here we propose the use of HLAB27 not for diagnosis but for screening. For this purpose HLA-B27 can be clearly regarded as a good screening parameter. Interestingly, in two earlier studies, a diagnosis of AS could be made in $30-40 \%$ of patients with chronic back pain and a positive test for HLA-B27, ${ }^{31}{ }^{32}$ a result very much in line with the calculations presented here.

We do not suggest the use of imaging such as $x$ ray examination or MRI of the sacroiliac joints for screening, because of costs, radiation exposure, and difficulties in interpretation. However, primary care physicians have sometimes an imaging result available in the process of investigating patients with low back pain. In such a case, if clear sacroiliitis is demonstrated by $x$ ray examination or MRI, patients should also be referred to a rheumatologist (fig 1 ).

We have recently discussed the possibility that the clinical symptom of IBP might be used as an entry parameter both for early diagnosis and screening of axial SpA. ${ }^{23}$ However, a sensitivity of no higher than $75 \%$ means that $25 \%$ of patients will be missed. Thus, we prefer now, based on the considerations presented here, to use IBP rather as a facultative parameter for screening (fig 1).

Obviously, if several of the screening parameters, or of the other parameters shown in table 1, are positive, the likelihood of having axial SpA increases. ${ }^{23}$ But asking for a combination of parameters for screening necessarily decreases the sensitivity, which will fall, for example, to around $68 \%$ if a combination of IBP plus positive HLA-B27 is used for screening. However, if the number of patients to be seen by the specialist (to make the diagnosis in one) has to be lower (according to the local conditions) such a combination of parameters could be used for screening, if a lower sensitivity is acceptable. But, suggestions for physicians in primary care on when to refer a patient should be simple and easy to follow and should identify most of the patients. Therefore, we think that the approach suggested here (fig l) is feasible and is likely to identify the great majority of patients with axial SpA among the large group of people with chronic back pain, if these patients are then seen subsequently by a specialist (normally a rheumatologist) for further diagnostic investigation. In addition to suggesting single and simple screening parameters to be used in primary care, physicians should be encouraged to refer patients with higher priority to a rheumatologist when several of these parameters are positive.

Recently, early referral recommendations for rheumatoid arthritis were published. ${ }^{33}$ These authors based their recommendations on a review of published reports, experiences from early arthritis clinics and, finally, on a consensus. We think that the approach presented here by us, based on sensitivity, LR, ease of interpretation, and costs of parameters used for screening, is a reasonable alternative and could also be used in other diseases. Studies are currently performed to test these recommendations among primary care physicians.

\section{Authors' affiliations}

J Sieper, M Rudwaleit, Medical Department I, Rheumatology, Campus Benjamin Franklin Charitè, University Medicine Berlin, Germany

\section{REFERENCES}

1 Feldtkeller E, Khan MA, van der Heiide D, van der Linden S, Braun J. Age at disease onset and diagnosis delay in HLA-B27 negative vs. positive patients with ankylosing spondylitis. Rheumatol Int 2003;23:61-6.

2 van der Linden S, van der Heijde D. Ankylosing spondylitis. Clinical features [review]. Rheum Dis Clin North Am 1998;24:663-76, vii.

3 van der Linden S, Valkenburg H, Cats A. The risk of developing ankylosing spondylitis in HLA-B27 positive individuals: a family and population study. Br J Rheumatol 1983;22(suppl 2):18-19.

4 Braun J, Bollow M, Remlinger G, Eggens U, Rudwaleit M, Distler A, et al. Prevalence of spondylarthropathies in HLA-B27 positive and negative blood donors. Arthritis Rheum 1998;41:58-67.

5 Gran JT, Husby G, Hordvik M. Prevalence of ankylosing spondylitis in males and females in a young middle-aged population of Tromso, northern Norway. Ann Rheum Dis 1985;44:359-67.

6 Dougados M, Dijkmans B, Khan M, Maksymowych W, van der Linden S, Brandt J. Conventional treatments for ankylosing spondylitis [review]. Ann Rheum Dis 2002;61(suppl III):iii40-50.

7 Haibel H, Rudwaleit M, Braun J, Sieper J. Six months open lable trial of leflunomide in active ankylosing spondylitis. Ann Rheum Dis 2005;64:124-6.

8 van der Heijde DMF, Wanders A, Spoorenberg A, van der Linden S, Dougados $M$, van der Tempel $H$, et al. Structural damage assessed on radiographs in patients with anklyosing spondylitis steadily increases over time [abstract]. Arthritis Rheum 2003;48(suppl):S175.

9 Amor B, Dougados M, Listrat V, Menkes CJ, Roux H, Benhamou C, et al. Are classification criteria for spondylarthropathy useful as diagnostic criteria? Rev Rhum Engl Ed 1995;62:10-15.

10 Dougados M, Behier JM, Jolchine I, Calin A, van der Heijde D, Olivieri I, et al. Efficacy of celecoxib, a cyclooxygenase 2-specific inhibitor, in the treatment of ankylosing spondylitis: a six-week controlled study with comparison against placebo and against a conventional nonsteroidal antiinflammatory drug. Arthritis Rheum 2001;44:180-5.

11 Braun J, Brandt J, Listing J, Zink A, Alten R, Golder W, et al. Treatment of active ankylosing spondylitis with infliximab: a randomised controlled multicentre trial. Lancet 2002;359:1 187-93.

12 van den Bosch F, Kruithof E, Baeten D, Herssens A, de Keyser F, Mielants H, et al. Randomized double-blind comparison of chimeric monoclonal antibody to tumor necrosis factor alpha (infliximab) versus placebo in active spondylarthropathy. Arthritis Rheum 2002;46:755-65.

13 Brandt J, Khariouzov A, Listing J, Haibel H, Sorensen H, Grassnickel L, et al. Six-month results of a double-blind, placebo-controlled trial of etanercept treatment in patients with active ankylosing spondylitis. Arthritis Rheum 2003;48: 1667-75

14 Davis JC Jr, van der Heijde D, Braun J, Dougados M, Cush J, Clegg DO, et al. Enbrel Ankylosing Spondylitis Study Group. Recombinant human tumor necrosis factor receptor (etanercept) for treating ankylosing spondylitis: a randomized, controlled trial, Arthritis Rheum 2003;48:3230-6.

15 Braun J, Baraliakos X, Golder W, Brandt J, Rudwaleit M, Listing J, et al. Magnetic resonance imaging examinations of the spine in patients with ankylosing spondylitis, before and after successful therapy with infliximab: evaluation of a new scoring system. Arthritis Rheum 2003;48:1126-36. 
16 Allali F, Breban M, Porcher R, Maillefert JF, Dougados M, Roux C. Increase in bone mineral density of patients with spondyloarthropathy treated with antitumour necrosis factor $\alpha$. Ann Rheum Dis 2003;62:347-9.

17 Rudwaleit M, Listing J, Brandt J, Braun J, Sieper J. Prediction of a major clinical response (BASDAI 50) to tumour necrosis factor $\alpha$ blockers in ankylosing spondylitis. Ann Rheum Dis 2004;63:665-70.

18 Underwood MR, Dawes P. Inflammatory back pain in primary care. Br J Rheumatol 1995:34:1074-7.

19 Deyo RA, Weinstein JN. Low back pain. N Engl J Med 2001;344:363-70.

20 van der Linden S, Valkenburg HA, Cats A. Evaluation of diagnostic criteria for ankylosing spondylitis. A proposal for modification of the New York criteria. Arthritis Rheum 1984;27:361-8.

21 Mau W, Zeidler H, Mau R, Majewski A, Freyschmidt J, Stangel W, et al. Clinical features and prognosis of patients with possible ankylosing spondylitis. Results of a 10-year followup. J Rheumatol 1988;15:1109-14.

22 Braun J, Bollow M, Eggens U, Konig H, Distler A, Sieper J. Use of dynamic magnetic resonance imaging with fast imaging in the detection of early and advanced sacroiliitis in spondylarthropathy patients. Arthritis Rheum 1994; 37: 1039-45

23 Rudwaleit $M$, van der Heijde D, Khan MA, Braun J, Sieper J. How to diagnose axial spondyloarthritis early. Ann Rheum Dis 2004;63:535-43.

24 Dougados M, van der Linden S, Juhlin R, Huiffeldt B, Amor B, Calin A, et al. The European Spondylarthropathy Study Group preliminary criteria for the classification of spondylarthropathy. Arthritis Rheum 1991;34:1218-27.
25 Calin A, Porta J, Fries JF, Schurman DJ. Clinical history as a screening test for ankylosing spondylitis. JAMA 1977;237:2613-14.

26 Amor B, Santos RS, Nahal R, Listrat V, Dougados M. Predictive factors for the longterm outcome of spondyloarthropathies. J Rheumatol 1994;21:1883-7.

27 van Tubergen A, Heuft-Dorenbosch L, Schulpen G, Landewé R, Wijers R, van der Heijde $D$, et al. Radiographic assessment of sacroiliitis by radiologists and rheumatologists: does training improve quality? Ann Rheum Dis 2003;62:519-25.

28 van der Heijde DMFM, Wanders A, Mielants $H$, Dougados $M$, Landewè RBM. Prediction of progression of radiographic damage over 4 years in patients with ankylosing spondylitis [abstract]. Ann Rheum Dis 2004;63(suppl I):98.

29 Gran JT, Nordvag BY. Referrals from general practice to an outpatient rheumatology clinic: disease spectrum and analysis of referral letters. Clin Rheumatol 2000;19:450-4.

30 Khan MA, Khan MK. Diagnostic value of HLA-B27 testing ankylosing spondylitis and Reiter's syndrome. Ann Intern Med 1982;96:70-6.

31 Jajic I. The role of HLA-B27 in the diagnosis of low back pain. Acta Orthop Scand 1979;50:411-13.

32 Sandstrom J, Andersson GB, Rydberg L. HLA-B27 as a diagnostic screening tool in chronic low back pain. Scand J Rehabil Med 1984;16:27-8.

33 Emery P, Breedveld FC, Dougados M, Kalden JR, Schiff MH, Smolen JS. Early referral recommendation for newly diagnosed rheumatoid arthritis: evidence based development of a clinical guide. Ann Rheum Dis 2002;61:290-7. 